\title{
Deafness in the developing world: the place of cochlear implantation
}

\author{
M B Tarabichi, C Todd*, Z Khan*, X Yang ${ }^{*}$, B Shehzad $\dagger$, M M Tarabichił
}

\begin{abstract}
Introduction: This paper attempts to review changes in the lives of hearing-impaired patients within the developing world, brought about by globalisation and development. The paper also explores limitations to improved care and addresses the collective moral responsibility of developed nations.

Methods: Analysis of literature.

Results: Within developing nations, large populations have emerged with a similar pattern of problems, access to information and aspirations as those living in developed nations. However, marked differences in income have persisted. These trends have resulted in a relative increase in the proportion of the hearing-impaired population in need of cochlear implantation, while at the same time restricting their access to such treatment.

Conclusions: The emergence of global markets and media and a shared sense of destiny amongst the people of this planet should translate into a concerted, worldwide effort to assist the deaf in developing countries. Much more can be done within existing resources and frameworks to improve the quality of these peoples' lives.
\end{abstract}

Key words: Deafness; Developing Countries; Cochlear Implants

\section{Introduction}

From hunger in the horn of Africa, to genocide in Bosnia, to the worldwide acquired immunodeficiency syndrome (AIDS) crisis, recent years have seen an emergence within developed nations of a sense of responsibility as global citizens. This has been brought about by an increased ability to access information and to act on issues affecting countries half a world away. In the last few decades, developments in technology and healthcare delivery systems have resulted in a greatly improved quality of life for hearing-impaired individuals in the developed world. In contrast, much of the deaf population in the developing world lacks basic human rights and is completely marginalised. Care-givers for the hearing-impaired have acted before as advocates on their behalf, especially for children, within their own communities and countries. Both developed and developing nations need to communicate across national borders, in order to understand the problems of the hearing-impaired in less developed nations, to share lessons learned in different communities and to find ways to improve the lives of hearing-impaired people across the globe.

This paper reviews the changes in patterns and causes of hearing loss which have been induced by economic change within developing nations. The paper also explores limitations to improved care and addresses the collective moral responsibility of developed nations.

\section{Analysis \\ Understanding the developing world}

The last 50 years have brought about tremendous change to the lives of millions of people in the developing world. Apart from sub-Saharan Africa, the gap between developing and developed nations has narrowed. Globally, literacy rates have improved and poverty has decreased.

The Human Development Index has been useful in stratifying countries and assessing them in terms of human well-being and economic progress. On this index, high-income Organization for Economic Co-operation and Development countries score highly (total Human Development Index $=0.946$ ), enjoying a relatively high life expectancy (79 years of age), low child (i.e. under five years of age) mortality rates and a high gross domestic product per capita (US\$32 003). ${ }^{1}$ China, Egypt, India and Pakistan are classified as having medium Human Development Indices, being 0.768, 0.702, 0.611 and 0.539, 
respectively. ${ }^{1}$ Of the 31 most poorly developed countries, 28 are located in sub-Saharan Africa, an area which has witnessed an increase in poverty and is the only region in the world in which the Human Development Index has not improved since 1990. ${ }^{1}$ However, there are early signs of economic progress within this region, with many violent conflicts ending and potential economic development emerging, especially in central Africa.

\section{Impact of development on the hearing disabled}

The development process itself has had far more impact on the prevalence of hearing impairment and its various causes, and on the life of the hearing-impaired, than any deliberate governmental, societal or international action. There are many aspects of this change to be considered. The first and foremost is its impact on the causes of hearing loss. The second is its impact on how the hearing-impaired view their disabilities and themselves. The third is its impact on an increasingly international marketplace and on the industries servicing the needs of the hearing-impaired.

\section{Impact of development on causes of hearing impairment}

The association of chronic otitis media with low socioeconomic status and poor healthcare has been widely documented within both developing and developed nations. ${ }^{2}$ Notwithstanding the presence of pockets of high prevalence within developed nations, the significance of chronic otitis media as a cause of hearing disability has decreased substantially (Table I). ${ }^{3}$ Within the developing world, one now sees a huge discrepancy in the prevalence of chronic ear disease, comparing city and rural areas, and within and outside pockets of development and prosperity. ${ }^{4}$ It is reasonable to predict further worldwide decline of the importance of this aetiology of hearing loss.

While aminoglycosides have been largely replaced over recent decades by more modern antibiotics with fewer side effects, they remain a clinical mainstay. In fact, they may be the most commonly used antibiotics worldwide, chiefly due to their use in developing

TABLE I

WORLDWIDE DISTRIBUTION OF CHRONIC OTITIS MEDIA

\begin{tabular}{ll}
\hline Population & Prevalence (\%) \\
\hline Highest prevalence & \\
Inuit & $12-46$ \\
Australian Aboriginal & $12-25$ \\
High prevalence & \\
Native American & $4-8$ \\
South Pacific Islander & $4-6$ \\
Africa & $3-6$ \\
Low prevalence & \\
Korea & 2 \\
India & 2 \\
Saudi Arabia & 1.4 \\
Lowest prevalence & \\
USA & $<1$ \\
UK & $<1$ \\
\hline
\end{tabular}

countries. Their high efficacy, coupled with extremely low cost, frequently make aminoglycoside antibiotics the only affordable drugs. Furthermore, since tuberculosis is on the rise worldwide, particularly in low income countries, aminoglycoside usage cannot be expected to reduce. ${ }^{5}$ As more people in developing nations abandon traditional healing practices in favour of western medical practices, with increased use of potent medications, a further rise in ototoxicity might be expected. In present day China, the importance of ototoxicity as a major cause of hearing impairment is shocking to most observers from developed nations. ${ }^{6}$

Asia is the dominant industrial production region in the world, with China being foremost by far. Many developing countries still use industrial organic solvents without adequate control, usually in an occupational setting where they are combined with other hazardous agents such as noise. ${ }^{7}$ In Asia, many factories use high concentrations of solvents in different industrial processes, the footwear industry being a good example. However, many of these factories do not control the levels of solvents used, and the environmental concentrations of these chemicals within workplaces may be totally unknown. Regulations concerning the use of ventilation systems and the provision of masks, gloves and other personal protective equipment do not exist in many of these countries.

In developed nations, excessive noise is at least partially the cause in more than one-third of cases of hearing impairment. Exposure to noise is also a significant cause of hearing loss in developing nations. People within these regions can be subjected to debilitating noise in factories, on construction sites, and from gunfire and fireworks. ${ }^{8}$ With the rise of China and the Far East as the world's manufacturing hub, there will be an increase in noise pollution affecting more workers in factories that lack basic safety requirements, basically repeating similar events that occurred in the early age of industrialisation in the West.

Congenital infection (e.g. cytomegalovirus, rubella and syphilis) is a common cause of hearing loss in developing nations. While the successful elimination of these three infections in countries such as Finland and the USA is well known, a number of developing countries (such as Cuba and Oman) have also achieved such elimination through careful implementation of rubella vaccination.' Improved general living conditions across the developing world are expected to further reduce the importance of congenital cytomegalovirus infections as a cause of hearing loss.

Immunisation against Haemophilus influenzae type $b$ and pneumococcus would prevent many cases of meningitis and its related complications. The load of $H$ influenzae type $\mathrm{b}$ meningitis has been reduced by 98 per cent in developed nations due to expanded immunisation programmes. In the West, improved medical care with corticosteroid therapy for children with meningitis has become an established practice shown to decrease the incidence of sensorineural hearing loss. It is hoped that 
improved basic community health and paediatric care will eventually have a similar impact within developing countries. ${ }^{10}$

Consanguinity has been shown to be associated with a doubling of the risk of genetic hearing loss. The process of industrialisation and increased mobility, together with altered social customs, are expected to change this pattern of marriage across much of the developing world, and specifically in Asia where it dominates. ${ }^{11}$

\section{Impact of development on the deaf community}

Social change is inextricably related to economic development. As in Europe, industrialisation and development has induced sweeping urbanisation in much of Asia. In China, Zeng and others have observed the perception of deafness purely as a disease or a handicap, and also the absence of any deaf culture or sense of identity. ${ }^{12}$ They have theorised that this might reflect the rural lifestyle of the majority of the population and the inability of the deaf to travel and congregate, as well as the less mature Chinese sign language system. This pattern seems to be changing in the cities, with communities of deaf people being anchored around specialised schools and factories for people with disabilities. Better means of communication and better access to global trends would further advance these changes. 6,12

\section{Impact of the global marketplace on services for the hearing-impaired}

Many healthcare products and services are traded globally in a similar fashion to other goods and services. In economic terms, the importance of any specific market to a supplier is based on that market's size and its purchasing power. The free market principles that have spurred much global development have also curtailed the ability of individual governments to dictate multinational suppliers' prices and business strategies. The development of global trading rules has further protected such companies' intellectual property and patent portfolios. Over the last 50 years in Europe, governments have taken on a greater role in providing for the healthcare of their citizens. However, this is unlikely to happen in developing nations, even as their economic fortunes improve. In such developing countries, many government decision-makers view any significant public spending on health as a restraint on the vitality of their economies. Thus, healthcare in developing nations is reliant, currently and probably permanently, on private finance from individual patients and their families. An increasingly global communications network has brought awareness of new technologies such as cochlear implants to a huge worldwide audience. However, in developing nations, the ability to pay for these services is much more limited, being restricted to the small section of the population with sufficient income. This is mainly due to the limited availability of private health insurance and the lack of consumer loans. This limited market for hearing devices within developing nations has resulted in the relevant medical equipment companies concentrating their operations within the developed nations, and extending their services in developing countries only to the select few who can afford them.

\section{Discussion}

The changes taking place in the developing world and the speed at which they are occurring are quite remarkable. These countries are made up of many communities with similar patterns of problems (health and otherwise), knowledge bases, information access and life aspirations as communities within the developed countries. The income discrepancy has persisted, especially when calculated in terms of the world main tradable currencies. These trends have produced a relative increase in the proportion of inherited forms of sensorineural hearing loss, compared with other causes of deafness, while at the same time restricting access to its only available treatment - cochlear implantation.

Cochlear implantation is one of the most successful, life-transforming and expensive clinical interventions in modern medicine. For many reasons, the various cochlear implant manufacturers have approached the marketing, pricing and development of cochlear implants in the same way as other medical devices, primarily focusing on the needs of developed nations, their healthcare financing schemes and regulatory environments. As this technology transfers to less developed countries, where most of the world's deaf population resides, the industry needs to reconsider its business practices.

Hearing-impaired patients, and society at large, have entrusted otolaryngologists, audiologists and speech therapists to be more than just care-givers. Medical practitioners are seen as, and have previously acted as, the primary advocates for these patients, especially for children. The moral responsibility of otolaryngologists living in the developed world extends well beyond their own communities and countries. Medical equipment companies have justifiably viewed this group of practitioners as their main 'constituency'. Such companies have designed their business and marketing plans in order to cater for deaf patients within developed countries, and their 'gate-keepers'. Thus, it would seem that otolaryngologists within developed nations are one of the few groups that can exert credible pressure on these companies to change their practices, in order to ensure better healthcare access for developing nations.

The increasingly global economy and marketplace has increased the interdependency between developed and developing nations. Many of the developed world's consumer goods originate in factories in Asia which may be contributing to workers' hearing disabilities. This would seem to indicate a degree of moral obligation on all developed nations to address these global issues.

A further issue is the financial health of the cochlear implant industry. Much of the development of these products has been financed by the industry 
itself. This industry's marketing effort has for the most part been ethical, and has helped disseminate information about this important new technology. In the authors' experience, such companies have focused on total patient care, rather than just attempting to sell their products, and seem to recognise their public and moral responsibilities. However, such companies need to be better persuaded if they are to reconsider the business tactics which have served them well for many years.

Cochlear implantation might not be a feasible treatment for a deaf child living in a remote village with no access to water or electricity. However, this stereotype does not reflect reality in much of the developing world. An Indian software engineer, who may in all likelihood be able to program a cochlear implant, would have to dedicate six years' income in order to afford such a device; an Indian teacher would have to dedicate 24 years' income.

In developing countries, access to alternative, nonverbal means of communication is more difficult for the hearing-impaired. The combination of a strong family- and geography-centred life and lack of educational and social outlets for the deaf usually results in their total marginalisation. For many of these individuals, cochlear implantation may provide a means of communicating verbally with the only circle of people they will ever know, implanted or not.

Access to such life-transforming health technology within the developing world has been a focus of intense public debate. The African AIDS crisis has forced regional governments and the pharmaceutical industry to find creative ways of delivering the required drugs to needy patients, through licensing initiatives and special programmes. This process was further cemented with the compulsory licensing of drugs provision under the World Trade Organization's Agreement on Trade-Related Aspects of Intellectual Property Rights.

Single-channel cochlear implant devices have been advocated as best for use within developing nations. The current body of evidence implies a significantly worse outcome, compared with multi-channel devices. While patients in developing countries might not be overly disadvantaged by not receiving the most current devices, the performance gap between single- and multi-channel devices is currently too wide to make use of the former acceptable.

China and India have both initiated programmes for developing their own affordable cochlear implant systems. However, early results from these programmes have not been encouraging. Basic challenges, such as reducing infection, increasing the number of channels, transcutaneous interface and hermetically sealing the device have not been met. In one particularly distressing study, 15 out of 17 devices were explanted because of infection. ${ }^{12}$ In our opinion, the human cost of developing an alternative implant is not ethically acceptable, given that the required technology and expertise has now been available for many years.

In children, no further meaningful auditory integration occurs beyond the age of seven years. Thus, for every five years of inaction, we lose the opportunity to treat a huge number of deaf children.

\section{Conclusions}

We believe that the emergence of global markets and media, and a shared sense of destiny amongst the people of this planet and responsibility should translate into a more concerted effort in both developed and developing nations to help the hearing-impaired. The pace of worldwide development has been breathtaking and has changed the nature of hearing disability. So much more can be done, using existing resources and within existing frameworks, to improve the lives of deaf people within the developing world. The time for action is now. Please join our online discussion of these issues on www.CIforAll.com.

\section{References}

1 Ross-Larson B, Coquereaumont M, Trott C, eds. Human Development Report. New York: Palgrave Macmillan, 2006

2 Chadha SK, Agarwal AK, Gulati A. A comparative evaluation of ear diseases in children of higher versus lower socioeconomic status. J Laryngol Otol 2006;120:16-19

3 Bock GR, Thylefors B, Smith AW. Prevention of Hearing Impairment from Chronic Otitis Media: Report of WHO/ CIBA Foundation Workshop. Geneva: World Health Organization, 1998

4 Ologe FE, Nwawolo CC. Chronic suppurative otitis media in school pupils in Nigeria. East Afr Med J 2003;80:130-4

5 Schacht J, Hawkins JE. Sketches of otohistory. Part 11: ototoxicity: drug-induced hearing loss. Rev Panam Salud Publica 2006;11:1-6

6 Callaway A. Deaf Children in China. Washington DC: Gallaudet University Press, 2000

7 Fuente A, McPherson B. Organic solvents in hearing loss: the challenge for audiology. Int J Audiol 2006;45:367-81

8 Smith AW, Henderson RH. Prevention of Noise Induced Hearing Loss: Report of an Informal Consultation. Geneva: World Health Organization, 1997

9 Robertson SE, Featherstone DA, Gacic-Dobo M. Rubella and congenital syndrome: global update. Rev Panam Salud Publica 2003;14:306-15

10 Smith R, Bale JF, White KR. Sensorineural hearing loss in children. Lancet 2005;365:879-90

11 Zakzouk S. Consanguinity and hearing impairment in developing countries: a custom to be discouraged. J Laryngol Otol 2002;116:811-16

12 Zeng FG. Cochlear implants in China. Audiology 1995;34: $61-75$

Address for correspondence:

Dr Muaaz Tarabichi,

American Hospital Dubai,

PO Box 5566,

Dubai, UAE.

Fax: 0097143096850

E-mail: mtarabichi@ahdubai.com

Dr M Tarabichi takes responsibility for the integrity of the content of the paper.

Competing interests: None declared 